\title{
Introduction: multilingualism and education: the critical nexus
}

\author{
Martin C Njoroge, Phyllis W Mwangi, Ruth W Ndung'u and Daniel O Orwenjo*
}

* Correspondence:

orwenjo@yahoo.com

Department of English and

Linguistics, Kenyatta University, P.O

Box 43844-00100, GPO, Nairobi,

Kenya

\section{Background}

This special thematic issue of Multilingual Education under the header, "Multilingualism and Education in Africa" journal focuses on practices and challenges that relate to multilingualism and education in the African continent. It represents an array of selected but representative international scholarly discourse on the twin issues of multilingualism and education in Africa by renowned experts on these issues. The contributions are based on empirical studies, theoretical postulations and policy interrogations thus making the journal an invaluable resource for anyone interested in multilingualism and education.

It is a universally accepted fact that language is just one of the many factors that can contribute to the delivery of quality education. Yet, while there are many factors involved in delivering quality basic education, language is clearly the key to communication and understanding in the classroom. It is also a linguistic and societal reality that many developing countries are characterized by individual as well as societal multilingualism, yet a majority of multilingual societies in Africa continue to experience and even propagate a paradoxical situation in which a single foreign language is allowed to dominate in the education sector. For most African countries and other post-colonies all over the world, this has always been (ridiculously) blamed on the colonial legacy.

Ridiculously, because some of these countries detached themselves from their colonial masters more than half a century ago, yet have done little to correct the situation. In Kenya, for instance, the newly independent nation asserted the hegemony of English over other local languages in her first post-independence education commission (Republic of Kenya, 1964, p.24). The commission concluded that, "they had no doubt about the advantages of English as a medium of instruction in the whole education process". Many other post-colonies made the same decision as Kenya; such decisions have been hinged mainly on what Penycook (2007, pp. 100-101) has called "the false promise of English" and the then desire to offer the former colonial subjects all that had been denied them by their colonizers. Like Kenya, after independence, many African countries had had to struggle with the central question of identity; in which language played a critical role. In making such decisions, the colonial history of specific African countries played a major role. Consequently, post-colonial countries took diverse, sometimes contradictory routes in drawing up language in education policies to guide their educational systems. These ranged from retaining the language of the former colonial powers in an official capacity, to ensuring limited space for it to minimize its 
impact on the establishment and development of the native language as the official and national language of the nation. Ghana, Nigeria and many of the other sub-Saharan countries took routes similar to that adopted by Kenya. In Cameroon, on the other hand, the merging of the former British and French colonies not only gave birth to a bilingual language in education policy, but also in other general sectors of life. Bamgbose (2003) sums up this contradictory scenario with regard to language in education policy in postcolonial African states:

Attention has been drawn to the fact that the logic of postcolonial policy is maintenance rather than change. While post-independence governments appear to be making language policy, most of the time they are only perpetuating colonial language policy. This inheritance situation has meant a futile struggle between change and continuity, with the latter usually gaining the upper hand. In almost all African countries colonized by Britain, English remains an official or co-official language (p. 422).

The situation described above has often led to instruction through a language that learners do not speak. This has been called "submersion" (Skutnabb-Kangas, 2000, p. 64) because it is analogous to holding learners under water without teaching them how to swim. Compounded by chronic difficulties such as low levels of teacher education, poorly designed, inappropriate curricula and lack of adequate school facilities, submersion makes both learning and teaching extremely difficult, particularly when the language of instruction is also foreign to the teacher (Benson, 2004). It is such inherent deficiencies of submersion that has seen many governments, and other education stake holders rethink the issue of language policy in education, resulting in wide ranging proposals, experiments and policy shifts toward either bilingual or various shades of multilingual education. The present volume takes stock of such policy shifts, experiments and proposals from an African perspective by looking at how various countries have attempted to introduce multilingual education in their respective education systems, the challenges that such attempts have encountered, and how such challenges have been addressed. This special series therefore, presents a valuable resource for best practices and how other attempts that have not done so well can borrow from such practices. This is because the twin issues of multilingualism and education, especially with regard to basic and primary education, are so central to the development of the child that they transcend the educational context to other spheres of life, such as human rights.

\section{The human rights perspective}

The Declaration of Human Rights, adopted by the United Nations General Assembly in 1948, contains a statement about Linguistic Human Rights as being one of the basic human rights. Inevitably, it therefore follows that countries which ratified the Declaration are duty bound to observe it and carry out policies in accordance with it. Such policies include language in education policies especially with regard to the language of instruction in early school years in countries (such as a number of sub-saharan countries) where former colonial languages are coexisting with local languages.

The Convention for the Rights of the Child became part of international law in 1990 and has since been ratified by 191 countries. The implication of this ratification is that 
over 96 percent of the children in the world live in countries that are legally bound to guarantee their full rights including civil, political, cultural, and economic. With specific regard to language and education, especially multilingual education, this provision demands that all children be given access to relevant and meaningful education, regardless of their background, where they live, or what language they speak (United Nations, 1990, p.32). The provision states thus:

In those states in which ethnic, religious or linguistic minorities or persons of indigenous origin exist, a child belonging to such a minority or who is indigenous shall not be denied the right, in community with other members of his or her group, to enjoy his or her own culture, to profess or practice his own religion, or to practice his or her own language (Convention on the Rights of the Child, Article 30).

Since the adoption of this convention, language rights activists and multilingual education proponents have noted, sadly, that although on the surface the provision appears to adequately secure the rights of the child with regard to language and education, it actually does not bind the states to use the language the child is most proficient in and the one he or she uses at home as the language of instruction. Emphasizing the need to extend such provisions to the classroom, Skutnabb-Kangas (1995, p. 625) observes:

In a civilized state, there should be no need to debate the right to maintain and develop mother tongue. It is a self evident, fundamental linguistic human right. Observing linguistic human rights...means the right to learn the mother tongue, orally and in writing, including at least basic education through the medium of mother tongue, and to use it in many official contexts. It also means the right to learn at least one of the official languages of the country of residence.

Such provisions on Linguistic Human Rights have proved to be insufficient in guaranteeing linguistic rights to minority populations. Consequently, in 1996, the World Conference of Linguistic Rights in Barcelona adopted the Universal Declaration of Linguistic Rights, the first universal declaration which specifically and clearly mentioned Linguistic Human Rights. In addition, the Universal Declaration of Linguistic Rights (UDLR) holds in regard several policies that motivated the respect of linguistic rights. The documents include:

- Declaration on the Rights of Persons belonging to National, Ethnic, Religious and Linguistic Minorities

- European Convention on Human Rights

- European Charter for Regional or Minority Languages

- Framework Convention for the Protection of National Minorities

- International Covenant on Civil and Political Rights

- Universal Declaration of the Collective Rights of Peoples

The above, in effect, makes the provision of mother tongue-based multilingual education a linguistic right, and by extension, a human right. It is with this background that this special issue interrogates how multilingual education has been or is being practiced in Africa, the challenges therein, and how such challenges have been addressed. 


\section{Pedagogical perspectives}

The use of a familiar language to teach beginning literacy facilitates an understanding of sound-symbol or meaning-symbol correspondence. This is especially so because learning to read is most efficient when students know the language and can employ psycholinguistic guessing strategies; likewise, students can communicate through writing as soon as they understand the rules of the orthographic (or other written) system of their language. In contrast, submersion programs may succeed in teaching students to decode words in the L2, but it can take years before they discover meaning in what they are "reading". Bilingual and multilingual as opposed to monolingual schooling offers significant pedagogical advantages which have been reported consistently in the academic literature. Such pedagogical benefits with regard to bilingual and multilingual education advantages are summarized in Benson (2004, pp. 2-4) as follows:

i. Since content area instruction is provided in the L1, the learning of new concepts is not postponed until children become competent in the L2. Unlike submersion teaching, which is often characterised by lecture and rote response, bilingual instruction allows teachers and students to interact naturally and negotiate meanings together, creating participatory learning environments that are conducive to cognitive as well as linguistic development. Explicit teaching of the L2 beginning with oral skills allows students to learn the new language through communication rather than memorization. In submersion schooling teachers are often forced to translate or code-switch to convey meaning, making concept learning inefficient and even impeding language learning, while bilingual programs allow for systematic teaching of the L2.

ii. Transfer of linguistic and cognitive skills is facilitated in bilingual programs. Once students have basic literacy skills in the L1 and communicative skills in the L2, they can begin reading and writing in the L2, efficiently transferring the literacy skills they have acquired in the familiar language. The pedagogical principles behind this positive transfer of skills are Cummins' $(1991,1999)$ interdependence theory and the concept of common underlying proficiency, whereby the knowledge of language, literacy and concepts learned in the L1 can be accessed and used in the second language once oral L2 skills are developed, and no re-learning is required. Consistent with these principles, it is possible for children schooled only in the L2 to transfer their knowledge and skills to the L1, but the process is highly inefficient as well as being unnecessarily difficult.

iii. Student learning can be accurately assessed in bilingual classrooms. When students can express themselves, teachers can diagnose what has been learned, what remains to be taught and which students need further assistance. In submersion schooling cognitive learning and language learning are confounded, making it difficult for teachers to determine whether students have difficulty understanding the concept itself, the language of instruction, or the language of the test.

iv. The affective domain, involving confidence, self-esteem and identity, is strengthened by use of the L1, increasing motivation and initiative as well as creativity. L1 classrooms allow children to be themselves and develop their personalities as well as their intellects, unlike submersion classrooms where they are forced to sit silently or repeat mechanically, leading to frustration and ultimately repetition, failure and dropout. 
v. Students become bilingual and biliterate. Bilingual programs encourage learners to understand, speak, read and write in more than one language. In contrast, submersion programs attempt to promote skills in a new language by eliminating them from a known language, which may actually limit learner competence in both.

Benson (2004) rightly observes that all of these advantages are based on two assumptions: one, that basic human needs are being met so that schooling can take place; and two, that mother tongue-based bilingual and multilingual schooling can be properly implemented. She goes on to note that simply changing the language of instruction without resolving other pressing social and political issues is not likely to result in significant improvement in educational services. The present volume therefore sets out to examine the state of the art with regard to multilingual practices from an African perspective in as far as such practices are concerned, and the challenges faced with a view to providing practitioners and policy makers with a framework of comparing the best practices and possible alternatives to unsuccessful models.

All in all, due to the varied scope that this special thematic issue espouses both in terms of the geographical regions it covers and the different experiences of the contributors, it offers valuable insights for language practitioners, policy makers, educationists, and other stakeholders with interests in multilingualism and education. It comes at a time when there is renewed global interest in the rights of children, including their fundamental rights to education in a language they can operate ineasily. It also comes at a time of increased interest in the rights of minority groups such as their right to preserve and promote their languages, not just as a part of their cultural heritage, but as inherent modes through which their hopes, fears and aspirations are expressed and their indigenous knowledge systems are developed and transmitted.

Competing interests

The authors declare that they have no competing interests.

Received: 20 April 2014 Accepted: 8 May 2014

Published: 19 August 2014

\section{References}

Bamgbose, A. 2003. A recurring decimal: English in language policy and planning. World Englishes 22(4): 419-431. Benson, C. 2004. Final report on bilingual education. Results of the external evaluation of the experiment in bilingual schooling in Mozambique (PEBIMO) and some results from bilingual adult literacy experimentation. Education Division Documents No. 8. Stockholm: Sida.

Cummins, J. 1991. Interdependence of first- and second-language proficiency in bilingual children. In Language processing in bilingual children (pp. 70-89), ed. E Bialystok. Cambridge: Cambridge University Press.

Cummins, J. 1999. Alternative paradigms in bilingual education research: Does theory have a place? Educational Researcher 28: 26-32.

Penycook, A. 2007. Critical applied linguistics: A critical introduction. New Jersey: Lawburn Erlbaum Associates.

Republic of Kenya. 1964. Kenya Education Commission Report: The Ominde Comission Republic of Kenya. Nairobi: Government Printers.

Skutnabb-Kangas, T. 1995. Review of linguistic minorities in multilingual settings: Implications for language policies. RELC Journal 26(2): 130-138.

Skutnabb-Kangas, T. 2000. Linguistic human rights and teachers of English. In The sociopolitics of English language teaching, ed. JK Hall and WG Eggington, 22-44. Clevedon: Multilingual Matters.

United Nations. 1990. Convention on the rights of the child. New York: United Nations.

doi:10.1186/s13616-014-0010-5

Cite this article as: Njoroge et al.: Introduction: multilingualism and education: the critical nexus. Multilingual Education 2014 4:10. 